\title{
Is the simulation theory of memory about simulation?
}

\section{Nikola Andonovski*}

\begin{abstract}
This essay investigates the notion of simulation and the role it plays in Kourken Michaelian's simulation theory of memory. I argue that the notion is importantly ambiguous and that this ambiguity may threaten some of the central commitments of the theory. To illustrate that, I examine two different conceptions of simulation: a narrow one (simulation as replication) and a broad one (simulation as computational modeling), arguing that the preferred narrow conception is incompatible with the claim that remembering involves the simulation of past episodes. Investigating possible solutions, I suggest that, despite some relatively serious consequences, the theory may be better off subscribing to the broad notion of simulation.
\end{abstract}

Keywords: Episodic Memory; Simulation Theory of Memory; Simulation

\section{Introduction}

Kourken Michaelian's simulation theory of memory (STM) is slowly becoming the leading post-causal theory of episodic memory. Put forward in the already seminal Mental Time Travel, STM characterizes episodic memory as a kind of imaginative simulation, performed by a cognitive system aiming to represent an episode from one's personal past. In this brief essay, I examine the notion of simulation and the role it plays in the simulation theory. I argue that the notion is importantly ambiguous and that this ambiguity may threaten some of the central commitments of STM. In section 1, I present the main features of the theory. In section 2, I present two different conceptions of simulation: a narrow one (simulation as replication) and a broad one (simulation as computational modeling). In section 3 , I set up the problem, arguing that the preferred narrow conception of simulation is incompatible with STM's representational commitments. Section 4 investigates possible solutions, suggesting that, despite some relatively serious consequences, STM may be better off subscribing to the broad notion of simulation.

\footnotetext{
*PhD student in Philosophy at Johns Hopkins University, Baltimore, USA. E-mail: nandono1@jhu.edu
} 


\section{The simulation theory of memory}

The idea that memory and imagination are intimately connected has a long history. Recent developments in psychology and neuroscience, however, have seen a particularly interesting variant of it rise to the fore. According to this variant, episodic memory and imagination are operations of a single cognitive system ${ }^{1}$. Michaelian ${ }^{2}$ takes his cue from these scientific developments, aiming to move decisively beyond classical preservationist theories of episodic memory ${ }^{3}$. Remembering, he tells us, "is not a matter of encoding, consolidation, storing and retrieving discrete representations of discrete episodes"4. It is, rather, a form of imaginative construction performed by a general cognitive system dedicated to the simulation of possible (past) episodes. According to his simulation theory of memory:

$S$ remembers an episode $e$ just in case:

1) $S$ now has a representation $R$ of $e$

2) $R$ is produced by a properly functioning episodic construction system, which aims to produce a representation of an episode belonging to $S$ 's personal past ${ }^{5}$.

Prima facie, condition (1) appears relatively uncontroversial. Yet, Michaelian doesn't tell us how (broadly) we should understand the notion of 'representation', highlighting only the origin of the relevant representations ${ }^{6}$. If $R$ is to be a memory of a past episode, it has to be produced by a properly functioning episodic system. And, while the representations produced by this system may have a particular character (format or content), how the notion is understood essentially depends on further facts about the system. A proper understanding of (1), thus, depends on a proper understanding of (2).

\footnotetext{
1 Cognitive systems are organized structures of elementary operating components, which may be individuated in terms of their underlying brain mechanisms, the kinds of information they process and the general laws and principles of their operation. For a good review of the relevant empirical evidence supporting the claim that memory and imagination are operations of a single cognitive system, cf. Schacter et al. (2012)

${ }^{2}$ MICHAELIAN, Mental Time Travel: episodic memory and our knowledge of the personal past.

${ }^{3}$ Michaelian (2016a) characterizes preservationism as "the view that remembering is essentially a matter of preserving content originally produced by another cognitive process" (p.68). On this characterization, most variants of the causal theory of memory qualify as preservationist. See also Michaelian \& Sutton (2017).

${ }^{4}$ MICHAELIAN, Mental Time Travel, p. 103.

${ }^{5}$ Idem, p. 107.

${ }^{6}$ This is not trivial. For comparison, Martin \& Deutscher (1966), in their seminal presentation of the classical causal theory of memory, work with an extremely broad conception of representation. On their conception, famously, painting qualifies as a form of representation.
} 
Let's, then, move to condition (2). STM makes much of "the growing consensus" in the recent science of memory ${ }^{7}$, taking episodic remembering to be an operation of a more general cognitive system, which underlies a number of psychological capacities. As Michaelian is well aware, however, this consensus belies an important theoretical diversity. Indeed, the last 25 years have seen the emergence of a variety of competing characterizations of the function and structure of this cognitive system. Perhaps most famously, Tulving ${ }^{8}$ takes the system to "make possible mental time travel [MTT] through subjective time", an activity in which the 'traveler' maintains her sense of self over time9. Schacter, Addis and colleagues ${ }^{10}$, in contrast, downplay the importance of subjective 'travel' through mental time. According to their constructive episodic simulation hypothesis (CESH), the general cognitive system is dedicated to the simulation of (possible) past and future events, which involves the flexible recombination of episodic details from previously experienced events. A related, yet importantly different, account has been proposed by Hassabis and Maguire ${ }^{11}$. On their scene construction theory (SCT), the primary function of the episodic system is the construction of atemporal scene representations, which may be put to different purposes: episodic remembering, imagination, spatial navigation etc.

Perhaps somewhat surprisingly, Michaelian's STM is not committed to any particular account of the episodic system, opting for theoretical neutrality. The theory is neutral in two distinct senses. First, it doesn't take a firm stand on the proper characterization - or indeed: explanatory centrality - of specific computational (i.e. constructive) processes ${ }^{12}$. That is to say, the simulationist doesn't have a horse in the race between MTT, CESH and SCT theorists. Second, and closely related, the theory doesn't wager on the implementational-level details of the episodic construction system ${ }^{13}$. Yet, the simulation theory "is meant to be sufficiently determinate to capture the common core" of the new systems approaches (ibid). The common core, as should be clear by now, is the commitment to viewing episodic remembering as a product of a general "episodic construction" system, whose function is not uniquely mnemonic. On the systems perspective, the identification of relevant (or even distinguishing features) of episodic

\footnotetext{
${ }^{7}$ MICHAELIAN, Mental Time Travel, p. 98.

8 TULVING, Episodic Memory and Autonoesis: Uniquely Human?, p. 9.

${ }^{9}$ Suddendorf \& Corballis (2007) build on this idea, characterizing memory and imagination as operations of a single cognitive system for mental time travel (MTT).

10 SCHACTER et al., Remembering the past to imagine the future: the prospective brain; Episodic simulation of future events: concepts, data and applications; The Future of memory.

${ }^{11}$ HASSABIS \& MAGUIRE, Deconstructing episodic memory with construction; The construction system of the brain.

12 MICHAELIAN, Mental Time Travel, p. 105-6.

${ }^{13}$ Idem, p. 106.
} 
memory is inherently tied to the identification of relevant features - computational operations, representations etc. - of this general system.

Is the simulation theory sufficiently determinate to capture the common core of these, often substantially different, approaches to the study of episodic memory? Answering this question properly requires an extended analysis of a number of distinct components of STM. For example, the notion of "proper function", which plays a key role in condition (2), is both complex and sneakily multifaceted. Michaelian does not shy away from this complexity, offering a comprehensive account that ties proper function to reliability. Thus, on STM, a properly functioning system is a reliable system, where reliability is understood as the tendency of the system to produce mostly accurate representations (in normal conditions) ${ }^{14}$. In the context of episodic remembering, specifically, the construction system is functioning properly if it tends to produce accurate representations of personal past episodes. While this proposal is undoubtedly intriguing, it is not clear how well it jibes with the commitments of some systems theorists who see systematic accuracy errors as adaptive features of a system attempting to maximize rememberers' predictive prowess ${ }^{15}$. Similar questions surface in the analysis of other concepts central to STM, including 'aim', 'episode' and even "personal past". And, while Michaelian has something to say about each of these notions, the same cannot be said about the notion that lends its name to his theory. What, namely, does the 'simulation' in "simulation theory" refer to? Surprisingly, given its frequent use in Mental Time Travel, the notion is not properly introduced or analyzed, even in the sections that present the simulation theory of memory. Perhaps, then, Michaelian intends to be non-committal about the notion, aiming for theoretical neutrality once again. But, is there a sufficiently determinate core sense of 'simulation' shared by the new systems theories? Indeed, what kind of process is simulation (considered to be)? What is its relationship to imagination? Can episodes of one's personal past be genuinely simulated, as STM proposes? Let's turn to these questions.

\section{What is simulation?}

The term 'simulation' has been used in a variety of ways in the philosophical and psychological literature. In a now classic paper, Stich \& Nichols lament the overly heterogeneous use of the concept in the mindreading debate: "the diversity among the theories, processes and mechanisms to which advocates of simulation theory have

\footnotetext{
${ }^{14}$ Cf. MiChaELIAN, Confabulating, Misremembering, Relearning: The Simulation Theory of Memory and Unsuccessful Remembering, p. 6.

${ }^{15} \mathrm{Cf}$. SCHACTER, The seven sins of memory: Insights from psychology and cognitive neuroscience; SCHACTER et al. The Future of memory; DE BRIGARD, Is memory for remembering? Recollection as a form of episodic hypothetical thinking.
} 
attached the label 'simulation' is so great that the term itself has become quite useless" 16 . One can hardly be dissuaded from such a pessimistic conclusion upon analysis of the ways in which the term has been used in the context of episodic memory. Interestingly, however, two of the main systems theories of episodic memory - indeed, two of the three approaches whose "common core" STM attempts to capture - do not rely on the notion of simulation at all. Thus, the term doesn't appear in Tulving's flagship expositions of the mental time travel view, with simulation not being one of the 'features' of episodic memory ${ }^{17,18}$. Similarly, scene construction theorists mention the term only in passing, and only to refer to the views of their rivals ${ }^{19}$. As you may expect, then, it is these rivals constructive episodic simulation theorists - that are mainly responsible for promulgating the connection between episodic memory and simulation ${ }^{20}$. Unfortunately, this has not thwarted the emergence of a problematic diversity of the kind Stich \& Nichols lamented. Indeed, even in (what appears to be) the clearest exposition of the commitments of CESH, Schacter and colleagues offer a number of different meanings of 'simulation', hastily, and somewhat confusingly, running them together ${ }^{21}$. To their credit, however, they end up settling on a preferred meaning, characterizing simulation as a kind of imaginative activity:

We use the term to refer to imaginative constructions of hypothetical events and scenarios... [Simulation] involves imaginatively placing oneself in a hypothetical scenario and exploring possible outcomes ${ }^{22}$.

This notion of simulation roughly corresponds to what Stich and Nichols called pretense-driven-offline-simulation ${ }^{23}$. When attempting to simulate a hypothetical scenario, the subject - or rather: the episodic system - acts on the 'pretense' that the scenario is actual, exploring its features by simulating the (various) ways in which such a scenario can unfold. It is in this sense that simulation is 'imaginative': it is a constructive process that

\footnotetext{
${ }^{16}$ STICH; NICHOLS, Cognitive penetrability, rationality and restricted simulation, p. 299.

${ }^{17}$ Cf. TULVING, Episodic Memory and Autonoesis: Uniquely Human?, p. 11

${ }^{18}$ To be fair, the term appears in Suddendorf \& Corballis (2007)'s exposition of the mental time travel view. Yet, the authors don't properly introduce or analyze the concept, despite providing a complex and multifaceted theater metaphor for mental time travel.

${ }^{19}$ Cf. HASSABIS; MAGUIRE, Deconstructing episodic memory with construction; The construction system of the brain.

${ }^{20}$ This, in itself, may be problematic if the goal is to capture the common core of these views.

${ }^{21}$ To give you a taste of this: Schacter et al. (2008) talk of simulation as an "inner anticipatory programming of... alternative behavioral modes" (p.40), as "imitative representation of the functioning or process of some event or some serious of events" (p.41) as well as a kind of "reenactment of sensory-motor states... to represent categories" (ibid). It is not clear how these notions relate to each other and whether they share a common core.

${ }^{22}$ SCHACTER, et al. Episodic simulation of future events: Concepts, data, and applications, p. 42, emphasis original.

${ }^{23}$ STICH; NICHOLS, Cognitive penetrability, rationality and restricted simulation, p. 303.
} 
operates on the pretend input that is fed to the system (e.g. the belief that one is 'in' the hypothetical scenario).

Of course, not every process that is pretense-driven and operates 'offline' is a simulation. Simulations are, above all, epistemic devices: they provide epistemically available processes that reflect the relevant aspects of processes that are not epistemically available in the same way ${ }^{24}$. The purpose of simulating, in other words, is to gain knowledge about a process/scenario that we don't have proper access to by relying on a process that we can access. For this to be possible, a simulation must be like the target process/scenario in some relevant way; it must somehow 'mirror' its underlying (causal) structure. Only in that case will the "possible outcomes" explored in the simulation be genuinely informative and anchor our expectations about what it would be like to experience such an event/scenario. Importantly, however, there are different ways in which a simulation process may be 'like' a target/simulated process. Consider these two kinds of simulation, discussed by Fisher:

a. A sophisticated computer simulation of airflow reflects the patterns of actual airflow well enough to enable accurate predictions of how planes will fly

b. Aerodynamics in a wind tunnel is sufficiently similar to aerodynamics in open air to allow us to make predictions of how actual planes will fly on the basis of what happens to model planes in a wind tunnel ${ }^{25}$.

In the case of (a), the similarity between the simulation and the simulated process is only a 'high-level', abstract similarity. The computer models the target process by "generating correct symbolic descriptions of its outputs from descriptions of its inputs by means of descriptions of its intervening states" 26 . Importantly, the simulating system need not operate according to the same principles the simulated process does; it only has to produce a correct description of its relevant outputs ${ }^{27}$. In contrast, the similarity in (b) is much deeper. The simulating process resembles the target one at a finer level of grain, 'mirroring' its basic principles of operation in advancing from state to state ${ }^{28}$. In this case, the simulation is, in a sense, a replication of the target process.

\footnotetext{
${ }^{24}$ Cf. SCHACTER, et al. Episodic simulation of future events: Concepts, data, and applications. See also, FISHER, Does Simulation Theory Really Involve Simulation?

${ }^{25}$ FISHER, Does Simulation Theory Really Involve Simulation?, p. 421.

${ }^{26}$ GOLDMAN, Simulating Minds: The Philosophy, Psychology, and Neuroscience of Mindreading, p. 35.

${ }^{27}$ As Goldman (id, ibid.) points out, computers are not governed by the laws of aerodynamics; they only generate symbolic descriptions of them.

${ }^{28}$ FISHER, Does Simulation Theory Really Involve Simulation?, p. 421.; GOLDMAN, Simulating Minds: The Philosophy, Psychology, and Neuroscience of Mindreading, p. 36.
} 
In the mindreading literature, 'simulation' is typically understood in the latter sense, as referring to a mental process that replicates (or 'duplicates', 'copies') another in some significant sense ${ }^{29}$. The reasons for this are easily illustrated. The debate between theory theorists (TTs) and simulation theorists (STs) concerns the way in which people reason, think and acquire knowledge about the mental states of others. While TTs argue that we rely on a "theory of mind" which we tacitly possess ${ }^{30}$, STs propose rather that we acquire knowledge about others' minds by simulating their mental states in our minds ${ }^{31}$. Now, if what is meant by 'simulation' is simply computational modelling, as in (a) above, this would make the claims of simulation theorists much less interesting. Indeed, on a computational view of the mind, these claims would border on the trivial, making every representation of others' minds a kind of simulation ${ }^{32}$. Simulating the mental states of others, then, must be taken to involve replication (or 'duplication', 'copying) of their internal states, a process which aims to resemble the target processes at a finer level of grain.

Predictably, the same issue arises in the context of episodic memory. So, do simulationists about memory aim to use the narrower notion of simulation-as-replication? Or are they content with a broader, but perhaps more problematic, notion of simulation? Unfortunately, neither Michaelian nor proponents of CESH discuss these issues explicitly ${ }^{33}$. Indeed, in their programmatic paper, Schacter and colleagues prefer to stay "neutral with respect to the various theoretical debates that exist concerning these related issues"34. Yet, at a risk of being repetitive, it is not clear whether this neutrality is properly earned and whether it can even be achieved. In fact, at first glance, it seems that simulationists must be committed to the replication view of simulation. The reasons for this claim mirror the ones illustrated above. Simulationists put a high premium on characterizing the specific form episodic simulations take, regularly emphasizing the characteristic phenomenology that accompanies such simulations. Thus, remembering is habitually portrayed as a kind of 're-experiencing' of a past personal event or scenario. On a computer-modelling notion of simulation, many claims of this kind will have to be interpreted quite liberally, often as providing only a metaphorical gloss on the core tenets of simulationism. Yet, a second glance is more disconcerting. Given some of Michaelian's

\footnotetext{
${ }^{29}$ Simulation, of course, cannot be reduced to simple duplication. One reason is that duplication/replication, unlike simulation, is symmetrical. This is one of the reasons why the "proper function" or 'aim' of the simulating process is important.

${ }^{30}$ Cf. GOPNICK; MELTZOFF, Words, thoughts, and theories; CARRUTHERS, Mindreading in Infancy

31 Cf. CURRIE; RAVENSCROFT, Recreative Minds: Imagination in Philosophy and Psychology. GOLDMAN, Simulating Minds: The Philosophy, Psychology, and Neuroscience of Mindreading

${ }^{32}$ Fisher (2006) makes a similar claim in a particularly interesting way.

33 Shanton \& Goldman (2010) do discuss these issues, which makes them unique among memory simulationists. See next section.

${ }^{34}$ SCHACTER, et al. Episodic simulation of future events: Concepts, data, and applications, p. 42.
} 
commitments in Mental Time Travel, it is not clear that the simulationist can opt for a replication view. To illustrate this, let's turn to another relatively straightforward question. Namely, what is it that is simulated by the episodic system, according to STM?

\section{Simulation of what? A problem}

On the simulation-as-replication conception, it is natural to see the episodic system as simulating past/future mental states or processes, associated with the experience of particular episodes. This is precisely the position Shanton \& Goldman ${ }^{35}$ develop in their brief treatment of the issue. Indeed, the authors see episodic remembering (and correspondingly: prospection) as a form of high-level mindreading, where the subject places herself, as it were, "in the shoes" of her past (and future) self. This process is straightforwardly analogous to the re-positioning that, according to STs, accompanies the reading of others' minds. Episodic remembering, to put it simply, is the mindreading of one's own past mental states. Shanton \& Goldman marshal evidence for three dimensions of resemblance "between processes involved in remembering previously experienced events (retrieval processes) and processes involved in the original experiences of the events (remembered processes)" 36 . Phenomenologically, remembering appears similar to past experiences of events. This is a familiar point in the memory/MTT literature, with remembering often characterized as a kind of re-experiencing a past event. Yet, the similarity between retrieval and remembered processes seems to run deeper. There are, in fact, good reasons to think that there are significant neural resemblances, with growing evidence that brain regions involved in an original experience of an event are (partially) reactivated when the event is later remembered ${ }^{37}$. Finally, Shanton \& Goldman argue that retrieval processes functionally resemble remembered processes, citing evidence of facilitation effects associated with the congruence of circumstances at encoding and retrieval ${ }^{38}$. The three dimensions of resemblance, they are adamant, afford "fairly direct evidence for a simulational account of memory" ${ }^{39}$.

Michaelian ${ }^{40}$ acknowledges that Shanton \& Goldman's account is "in tune" with his STM. Yet, he opts for a different route, effectively sidestepping the empirical considerations offered above:

\footnotetext{
${ }^{35}$ SHANTON; GOLDMAN, Simulation theory.

${ }^{36}$ Idem, p. 532.

${ }^{37}$ For a review, cf. DANKER; ANDERSON, The ghosts of brain states past: Remembering reactivates the brain regions engaged during encoding

${ }^{38}$ For details, see SHANTON; GOLDMAN, Simulation theory, p. 531 - 535.

${ }^{39}$ Idem, p. 533.

${ }^{40}$ MICHAELIAN, Mental Time Travel.
} 
Shanton and Goldman treat episodic memory as being a matter of simulating one's past mental states, in particular. On the simulation theory, in contrast, episodic memory enables us to simulate past episodes in general. This represents a fundamental advantage of the present simulation theory, for, while episodic memory is sometimes a matter of remembering past mental states, one often remembers events as such ${ }^{41}$.

The "fundamental advantage" pertains to the content of episodic memories. According to Michaelian, the representational arrow in episodic memory is not necessarily directed inwards, towards one's own previous experiences. It can be - and, in fact, it primarily is - directed outwards: towards past events as such ${ }^{42}$. For example, in remembering my trip to Brussels from last year, I can remember what happened during the trip without remembering the experiences, thoughts or feelings I had during the trip. Cases like this, Michaelian argues, illustrate that remembering is unlikely to reduce "to reading one's own past self's mind"43.

On STM, then, the episodic construction system should be understood as aiming to represent episodes from the rememberer's personal past, only some of which may be constituted exclusively by past mental states or processes. Now, a careful reader will notice that the shift away from Shanton and Goldman's simulationism is a bit more dramatic than Michaelian portrays it to be. Namely, while they acknowledge that 'high-level' mindreading involves the simulation of mental states which typically have propositional contents $^{44}$, Shanton \& Goldman have very little to say about the contents of episodic memories. Their emphasis is, rather, on the process of re-enactment of past mental states, which they take to be at the heart of remembering. In contrast, Michaelian places the content of episodic memories at the center of attention, linking it directly to the simulation process. Thus, in his comment above, he doesn't talk about the process of simulation as generating memory representations with specific contents, as one may expect from STM's condition (1). Rather, he takes the representing process itself to be simulational in character. Consequently, he is able to talk about the simulation of past episodes, in a way, indeed, reminiscent of Schacter et al.'s (2008) talk of the "imaginative construction of hypothetical events and scenarios" 45 .

Yet, on this interpretation, Michaelian's simulation theory of memory cannot be committed to a replication view of simulation ${ }^{46}$. If 'simulation' is understood in this

\footnotetext{
${ }^{41}$ Idem, p. 115, emphasis original.

${ }^{42}$ Importantly, this does not entail that past mental states cannot be remembered. It only entails that 'external' past events can be remembered.

${ }^{43}$ Idem, ibidem.

${ }^{44}$ SHANTON; GOLDMAN, Simulation theory, p. 528. See also: GOLDMAN, Joint Ventures: Mindreading, Mirroring, and Embodied Cognition, chapter 4.

${ }^{45}$ SCHACTER, et al. Episodic simulation of future events: Concepts, data, and applications, p. 42, emphasis added.

${ }^{46}$ Note: this is the case for CESH theorists as well
} 
narrow sense - i.e. as a kind of copying or duplication - then the episodic construction system cannot be taken to simulate past episodes/events. Remember: this notion of simulation entails a fine-grained resemblance between the principles of operation governing the simulating process and those governing the simulated process/scenario. Now, there are many rival metaphysical conceptions of events, as well as of their underlying 'structure' ${ }^{47}$. But, regardless of which conception one ultimately endorses, there is no reason to think that the principles of operation governing episodic simulation will end up mirroring the underlying structure of the (purportedly) simulated events. To paraphrase Goldman ${ }^{48}$, what transpires in the mind when one remembers a trip to Brussels bears little interesting resemblance to Brussels or holiday trips in general. The episodic construction system, in short, is unlikely to produce simulated 'replicas' of personal past episodes. STM, then, seems to face a troubling dilemma: either opt for a more liberal, but potentially excessively broad, notion of simulation or alter the basic commitments pertaining to the representation of past episodes. What are on the options on the table for the simulationist? And, which one of these options is most attractive?

\section{STM and simulation: theoretical options}

The simulationist may insist that past events, or at least some important feature of them, can be genuinely re-enacted or replicated. There is, indeed, one obvious candidate feature: time. Simulations of past events, just like the events themselves, are temporally extended; they, as it were, 'unfold' in time. Consequently, episodic remembering may be taken to necessarily involve a fine-grain replication of the temporal organization and structure of the remembered events. This route has been explored by a variety of contemporary theorists. Thus, Cheng \& Werning ${ }^{49}$ suggest that mnemonic representations are simulational in virtue of the fact that they represent the temporal succession (in the 'micro-structure') of episodes by temporal succession in the domain of representational vehicles $^{50}$. Similarly, De Brigard and Gessell ${ }^{51}$ argue that memory representations have a dynamic structure, unfolding in time and, hence, 'mirroring' the temporal structure of the

\footnotetext{
${ }^{47}$ Cf. CASATI; VARZI, Events.

${ }^{48}$ GOLDMAN, Simulating Minds: The Philosophy, Psychology, and Neuroscience of Mindreading, p. 38.

${ }^{49}$ CHENG; WERNING, What is Episodic Memory If It is a Natural Kind?

${ }^{50}$ Cheng \& Werning (2016) define an episode as an ordered list of events, where the principle of ordering is temporal succession. According to them, mnemonic simulations represent such temporal succession via a temporal succession of representational vehicles. Specifically, the authors suggest that populations of hippocampal cells firing in temporal sequence may represent the sequences of events in given episodes (their 'micro-structure').

${ }^{51}$ DE BRIGARD; GESSEL, Time is not of the essence: Understanding the neural correlates of mental time travel.
} 
represented (past) events ${ }^{52}$. While these proposals are intriguing, it is unlikely that they will afford a full resolution of the problem we've sketched. For one, they only isolate one feature of events that can be replicated, a feature that may be essential yet is clearly not distinguishing. (Note: past mental states/experiences too are temporally extended). More importantly, it is not obvious that temporally extended memory representations do manage to replicate, at a fine enough grain, the temporal structure of remembered events. They may, indeed, unfold in time, but the neural mechanisms that support such unfolding - e.g. theta-phase precession and time cells ${ }^{53}$ - are importantly dissimilar to the ones that anchor the temporal unfolding of 'external' events. To reach for Goldman once again, what transpires in the mind when one remembers an event will probably not resemble that event in any interesting way. To that extent, representations with a dynamic structure will not be genuine replications.

Another option is to simply follow Shanton \& Goldman, taking episodic simulation to involve the replication of past mental states/events. Given STM's explanatory ambition, however, Michaelian would not be keen on conceding that remembering does reduce to 'reading' one's own past self's mind. Is there a way out? One promising route involves the separation of the representation relation from the simulation process. Consider one tentative variant: in episodic memory, we remember past episodes by simulating the relevant past experiences associated with them. This "best of both worlds" solution attempts to preserve the semantic commitments of STM - memories are about episodes, not mental states while not sacrificing the evidence for mental process similarity. (Notice that, as things stand now, Michaelian is forced to jettison Shanton \& Goldman's argumentative strategy, sketched above). Moreover, such a view has the added benefit of being compatible with a non-representational account of simulation, which may be appealing to simulationists of a particular bent ${ }^{54}$. Nevertheless, this is only a provisional, and highly schematic, proposal. A serious simulationist account, developed along these lines, would owe us answers to a number of tricky, yet important, questions. What exactly does it mean to say that we remember episodes by simulating past experiences? How is the representational relation to these past episodes established? What does an account of this kind tell us about the representation of future episodes? Lastly, and perhaps crucially, doesn't this modified

\footnotetext{
${ }^{52}$ Interestingly, De Brigard and Gessell (2016) suggest that the scene construction theory (SCT) should be understood as a theory of the structure of memory representations (i.e. the representational vehicles), while the constructive episodic simulation hypothesis (CESH) is better understood as a theory about the content of memory representations. If they are right, this may have interesting consequences for the project of locating the "common core" of the systems approaches to episodic memory.

${ }^{53}$ For details, cf. SKAGGS et al. Theta phase precession in hippocampal neuronal populations and the compression of temporal sequences; MacDONALD et al, Hippocampal "time cells" bridge the gap in memory for discontiguous events.

${ }^{54}$ Cf. MICHAELIAN; SANT'ANNA, Memory without content? Radical enactivism and (post)causal theories of memory.
} 
STM - by separating the semantic and the psychological story - steer a little too far from its philosophical core? The devil, as always, is in the details.

Alternatively, Michaelian may simply bite the bullet and concede that episodic simulations do not aim to replicate the fine-grained structure of remembered events. This move towards a broader, but weaker, notion of simulation would preserve some of the basic metaphysical commitments of STM (most notably: the rejection of the necessity of appropriate causation in memory). It would also allow the simulationist to examine the representation of (past) events - i.e. the semantic story - without excessive concern for the mechanisms or vehicles of mnemonic representation. Indeed, this may be the "theoretical neutrality" Michaelian is after. Yet, this solution too may come at a (potentially steep) price. First, the simulationist would have to acknowledge that episodic remembering involves 'simulation' only in a somewhat attenuated sense, bracketing loose talk of 'reexperiencing' the past and 'pre-experiencing' the future. Of course, STM may still appeal to the specific format of the representations generated by the "episodic construction" system and may even resort to considerations of a more traditional sort to capture the character of mnemonic representations - e.g. by invoking sensory imagery. Yet, absent a careful and extended treatment of these ideas, the role of 'simulation' in episodic remembering remains tenuous. This ties in to the second concern. While prima facie dialectically satisfying, this solution may potentially clash with the positive accounts provided by systems theories like CESH and SCT. Namely, these theories may appeal to specific kinds of representations and operations proprietary to the episodic system - even to simulations, in the narrow sense. If the goal of STM is to capture the "common core" of these approaches, then for a broad notion of simulation may not end up being feasible. In short, the deflationary solution - i.e. simulation theory is not really about simulation - may be too deflationary.

Cards on the table. Which one of these theoretical avenues is most promising, and appropriate, for the simulation theory of memory? Given the explanatory ambitions of the theory, it seems likely that Michaelian would opt for rejecting the narrow simulation-asreplication view as simply too restrictive (and perhaps even too committal). Indeed, despite the nod to Shanton \& Goldman, I strongly suspect that STM was never intended to be "in tune" with replication/re-enactment views of remembering. Yet, Michaelian still owes us a careful, and systematic, treatment of these issues. This is not for nominal purposes only (is STM about simulation?); rather, it is necessary for a proper understanding of some of the theory's central commitments. Here, I will briefly mention a single issue. Importantly, STM is not content with treating episodic memories and imaginings as mental occurrences of the same kind (as products of a single cognitive system). Rather, the theory advances a stronger claim, characterizing episodic remembering as a kind of imagination. 
Now, while this makes for a memorable slogan, not much is offered in defense of it ${ }^{55}$. In fact, in advancing the claim, Michaelian seems to use 'imagination' to refer to the very process(es) of episodic construction - i.e. simulation - purportedly performed by the general episodic system. In that sense, to say that remembering is "a matter of imagining the past" is simply to say that it is a product of such episodic simulation ${ }^{56}$. But, if "episodic simulation" is to be understood broadly - i.e. as referring to any 'offline' construction of mental representations - then Michaelian's claim ends up not being as interesting (or sexy) as it may appear at first glance. To put the point somewhat provocatively: given a sufficiently broad notion of 'simulation', episodic remembering will trivially be a kind of imaginative simulation ${ }^{57}$.

\section{Conclusion}

In constructing his simulation theory of memory, Kourken Michaelian offers a curious mix of philosophical minimalism and grand explanatory ambition. As a result, the gap between the letter and the spirit of the theory can, at times, be uncomfortably large. In this brief essay, I tried to make one aspect of this gap visible to the naked eye by investigating the role the notion of simulation plays in the theory. Following the letter of the theory, we see a stripped-down variant of the notion, catering to the sensibilities of philosophical minimalists. Yet, the vibrant spirit of the theory pulls Michaelian towards commitments that he may not be able to deliver on upon the backdrop of such a minimal notion. Pointing to the different options on the table, I examined some ways in which the simulationist can close this uncomfortable gap. Choices have to be made.

\section{Acknowledgments}

Many thanks to Kirk Michaelian and the anonymous referees for their generous help with this essay.

\footnotetext{
${ }^{55}$ Cf. MICHAELIAN, Mental Time Travel, p. $106-110$.

${ }^{56}$ Idem, p. 60.

${ }^{57}$ Michaelian (personal communication) points out that the slogan "memory is a kind of imagination" is primarily meant to illustrate the contrast between STM and the causal theory of memory. On STM, unlike on the causal theory, episodic memories needn't be appropriately causally connected to the remembered past events. It is in this respect that episodic. memory is "not fundamentally different" from imagination. This is an important clarification of the explanatory commitments of STM. Yet, if my analysis above is correct, the slogan may not reflect these commitments well. Hence, on the broad conception of imaginative simulation, episodic memory may turn out to be a kind of imagination even if it does require appropriate causation (cf. Hopkins 2018 for a view of this kind). On a narrow conception, conversely, episodic memory may not be a kind of imagination even if it doesn't require appropriate causation. A lot, then, seems to hinge on the conception of simulation (and imagination) one endorses.
} 


\section{References}

CARRUTHERS, P. Mindreading in Infancy. Mind \& Language 28(2): 141-172, 2013.

Casati, R., \& Varzi, A. Events. In: ZALTA, E. N. (Ed.), The Stanford Encyclopedia of Philosophy (Winter 2015). Retrieved from: https://plato.stanford.edu/archives/win2015/entries/events/

CHENG, S., \& WERNING, M. What is Episodic Memory If It is a Natural Kind? Synthese, 193(5), 1345-1385, 2016. https://doi.org/10.1007/s11229-014-0628-6

CURRIE, G. \& RAVENSCROFT, I. Recreative Minds: Imagination in Philosophy and Psychology. Oxford: Oxford University Press, 2002

DANKER, J. F., \& ANDERSON, J. R. The ghosts of brain states past: Remembering eactivates the brain regions engaged during encoding. Psychological Bulletin, 136(1), 87-102, 2010. https://doi.org/10.1037/a0017937

DE BRIGARD, F. Is memory for remembering? Recollection as a form of episodic hypothetical thinking. Synthese, 191(2), 155-185, 2014. https://doi.org/10.1007/s11229-013$\underline{0247-7}$

De Brigard, F., \& Gessell, B. S. Time is not of the essence: Understanding the neural correlates of mental time travel. In: MICHAELIAN, K., KLEIN, S., SZPUNAR, K. Seeing the future: Theoretical perspectives on future-oriented mental time travel. Oxford: Oxford University Press, $\quad 2016, \quad$ p. 153-179. https://doi.org/10.1093/acprof:oso/9780190241537.003.0008

FISHER, J. C. Does Simulation Theory Really Involve Simulation? Philosophical Psychology: Vol 19, No 4, 2006.

GOLDMAN, A. I. Simulating Minds: The Philosophy, Psychology, and Neuroscience of Mindreading. Oxford: Oxford University Press, 2006.

GOLDMAN, A. I. Joint Ventures: Mindreading, Mirroring, and Embodied Cognition. Oxford: Oxford University Press, 2013.

GOPNIK, A., \& MELTZOFF, A. N. Words, thoughts, and theories. Cambridge, MA: The MIT Press, 1997.

HASSABIS, D., \& MAGUIRE, E. The Construction System of the Brain. Philosophical Transactions of the Royal Society of London. Series B, Biological Sciences, 364, 1263-1271, 2009. https://doi.org/10.1098/rstb.2008.0296 
HASSABIS, D., \& MAGUIRE, E. A. Deconstructing episodic memory with construction. Trends in Cognitive Sciences, 11(7), 299-306, 2007. https://doi.org/10.1016/j.tics.2007.05.001

Hopkins, R. Imagining the Past: On the Nature of Episodic Memory. In: DORSCH, F. M. F. (Ed.), Memory and Imagination. Oxford: Oxford University Press, 2018.

MACDONALD, C. J., LEPAGE, K. Q., EDEN, U. T., \& EICHENBAUM, H. Hippocampal "time cells" bridge the gap in memory for discontiguous events. Neuron, 71(4), 737-749, 2011. https://doi.org/10.1016/j.neuron.2011.07.012

MARTIN, C. B., \& DEUTSCHER, M. Remembering. The Philosophical Review, 75(2), 161196, 1966. https://doi.org/10.2307/2183082

MICHAELIAN, K. Mental Time Travel: Episodic Memory and Our Knowledge of the Personal Past (1 edition). Cambridge, Massachusetts: The MIT Press, 2016a.

MICHAELIAN, K. Confabulating, Misremembering, Relearning: The Simulation Theory of Memory and Unsuccessful Remembering. Frontiers in Psychology, 7, 2016b. https://doi.org/10.3389/fpsyg.2016.01857

MiChAEliAn, K. \& SUTtON, J. Memory. In: ZALTA, E. N. (Ed.), The Stanford Encyclopedia of Philosophy (Summer 2017). Retrieved from https://plato.stanford.edu/archives/sum2017/entries/memoryl

MICHAELIAN, K., \& SANT'ANNA, A. Memory without content? Radical enactivism and (post)causal theories of memory. Synthese. 2019 https://doi.org/10.1007/s11229-019-02119-7

SCHACTER, D. L. The seven sins of memory: Insights from psychology and cognitive neuroscience. American Psychologist, 54(3), 182-203, 1999. https://doi.org/10.1037/0003$\underline{066 X .54 .3 .182}$

SCHACTER, D. L., ADDIS, D. R., \& BUCKNER, R. L. Remembering the past to imagine the future: The prospective brain. Nature Reviews: Neuroscience, 8(9), 657-661, 2007. https://doi.org/10.1038/nrn2213

SCHACTER, D. L., ADDIS, D. R., \& BUCKNER, R. L. Episodic simulation of future events: Concepts, data, and applications. Annals of the New York Academy of Sciences, 1124, 39-60, 2008 https://doi.org/10.1196/annals.1440.001

SCHACTER, D. L., ADDIS, D. R., HASSABIS, D., MARTIN, V. C., SPRENG, R. N., \& SZPUNAR, K. K. The Future of Memory: Remembering, Imagining, and the Brain. Neuron, 76(4), 677-694, 2012. https://doi.org/10.1016/j.neuron.2012.11.001

SHANTON, K., \& GOLDMAN, A. Simulation theory. Wiley Interdisciplinary Reviews. Cognitive Science, 1(4), 527-538, 2010. https://doi.org/10.1002/wcs.33 
SKAGGS, W. E., MCNAUGHTON, B. L., WILSON, M. A., \& BARNES, C. A. Theta phase precession in hippocampal neuronal populations and the compression of temporal sequences. Hippocampus, 6(2), 149-172, 1996.

STICH, S., \& NICHOLS, S. Cognitive penetrability, rationality and restricted simulation. Mind \& Language, 12(3-4), 297-326, 1997. https://doi.org/10.1111/1468-0017.00050

SUDDENDORF, T., \& CORBALLIS, M. C. The evolution of foresight: What is mental time travel, and is it unique to humans? The Behavioral and Brain Sciences, 30(3), 299-313; discussion 313-351, 2007 https://doi.org/10.1017/S0140525X07001975

TULVING, E. Episodic memory: From mind to brain. Annual Review of Psychology, 53, 125, 2002 https://doi.org/10.1146/annurev.psych.53.100901.135114

Tulving, E. Episodic Memory and Autonoesis: Uniquely Human? In: TERRACE, H.S., METCALFE, J. The missing link in cognition: Origins of self-reflective consciousness. Oxford: Oxford University Press, 2005, p. 3-56, https://doi.org/10.1093/acprof:oso/9780195161564.003.0001 